\title{
Target attainment of cefotaxime in critically ill children with meningococcal septic shock as a model for cefotaxime dosing in severe pediatric sepsis
}

\author{
Stan J. F. Hartman ${ }^{1}$ (D) Navin P. Boeddha ${ }^{2,3} \cdot$ Ebru Ekinci $^{3} \cdot$ Birgit C. P. Koch $^{4} \cdot$ Rogier Donders $^{5} \cdot$ Jan A. Hazelzet $^{2}$. \\ Gertjan J. Driessen ${ }^{3,6} \cdot$ Saskia N. de Wildt ${ }^{1,2}$
}

Received: 2 January 2019 / Accepted: 11 March 2019/Published online: 9 April 2019

(C) The Author(s) 2019

\begin{abstract}
Reduced target attainment of $\beta$-lactam antibiotics is reported in critically ill patients. However, as target attainment of cefotaxime in severely ill pediatric sepsis patients may differ from adults due to age-related variation in pharmacokinetics, we aimed to assess target attainment of cefotaxime in this pilot study using meningococcal septic shock patients as a model for severe sepsis. Secondary analysis of prospectively collected data from a randomized controlled trial. Children with meningococcal septic shock ( 1 month to 18 years) included in this study received cefotaxime $100-150 \mathrm{mg} / \mathrm{kg} /$ day as antibiotic treatment. Left-over plasma samples were analyzed using LC-MS/MS to determine cefotaxime concentrations. MIC values from EUCAST were used to determine target attainment of cefotaxime for Neisseria meningitidis $(0.125 \mathrm{mg} / \mathrm{l})$, but also for Streptococcus pneumoniae $(0.5 \mathrm{mg} / \mathrm{l})$, Enterobacteriaceae $(1 \mathrm{mg} / \mathrm{l})$, and Staphylococcus aureus $(4 \mathrm{mg} / \mathrm{l})$. Target attainment was adequate when all samples exceeded MIC or fourfold MIC values. One thirty-six plasma samples of 37 severe septic shock patients were analyzed for cefotaxime concentrations. Median age was 2 years with a median PRISM-score of 24 and mortality of $24.8 \%$. The median unbound cefotaxime concentration was $4.8 \mathrm{mg} / 1$ (range 0-48.7). Target attainment ranged from 94.6\% for the MIC of N. meningitidis to $16.2 \%$ for fourfold the MIC S. aureus. Creatinine levels were significantly correlated with cefotaxime levels. Target attainment of cefotaxime with current dosing guidelines seems to be adequate for N. meningitidis but seems to fail for more frequently encountered pathogens in severely ill children.
\end{abstract}

Keywords Cefotaxime $\cdot$ Pharmacokinetics $\cdot$ Target attainment $\cdot$ Critically ill children $\cdot$ Sepsis

Stan J. F. Hartman

Stan.Hartman@radboudumc.nl

1 Department of Pharmacology-Toxicology, Radboudumc, Geert Grooteplein Zuid 10, 6525 GA Nijmegen, The Netherlands

2 Intensive Care and Department of Pediatric Surgery, Erasmus MC-Sophia Children's Hospital, University Medical Center Rotterdam, Rotterdam, The Netherlands

3 Department of Pediatrics, Division of Pediatric Infectious Diseases and Immunology, Erasmus MC-Sophia Children's Hospital, University Medical Center Rotterdam, Rotterdam, The Netherlands

4 Department of Pharmacy, ErasmusMC, Rotterdam, The Netherlands

5 Department for Health Evidence, Radboudumc, Nijmegen, The Netherlands

6 Department of Pediatrics, Juliana Children's Hospital, Haga Teaching Hospital, The Hague, The Netherlands

\section{Introduction}

Studies on the target attainment of $\beta$-lactam antibiotics in critically ill adult patients indicate that up to $41 \%$ do not achieve adequate plasma levels [1]. Pharmacokinetic studies in critically ill children have shown reduced target attainment of several, frequently used, antibiotics as well [2-4]. To our knowledge, only one recent study investigated target attainment of cefotaxime, in a relatively stable PICU cohort [5].

This reduced target attainment is a direct result of pathophysiological changes during critical illness, causing an increase in the volume of distribution, clearance, or both [6]. The risk of non-target attainment is particularly high for $\beta$ lactam antibiotics, due to their time-dependent kill characteristics [7].

Meningococcal sepsis is characterized by a severe, rapid onset of sepsis and multi-organ failure, with a high mortality 
rate (25-30\%) and long-term sequelae in 11-19\% of survivors [8]. Although the incidence of meningococcal sepsis has rapidly declined due to vaccination for Neisseria meningitidis, data from these patients can serve as a model for severe sepsis in critically ill children and guide optimal antibiotic dosing.

The aim of this study was to identify target attainment of cefotaxime for $N$. meningitidis in critically ill children with meningococcal sepsis and to extrapolate to target attainment for other frequently encountered pathogens in pediatric sepsis.

\section{Materials and methods}

\section{Setting}

We conducted a secondary analysis of data from a randomized, double-blinded, placebo-controlled phase 2 trial (RCT) designed to assess the activation process of protein $\mathrm{C}$ in critically ill children with meningococcal septic shock [9]. Children were randomized to receive placebo or protein $\mathrm{C}$ in addition to standard care for septic shock including antibiotic treatment with cefotaxime $100-150 \mathrm{mg} / \mathrm{kg} / \mathrm{day}$ in 3-4 doses.

Thirty-eight children aged 1 month to 18 years were recruited in the PICU of the Erasmus MC- Sophia Children's Hospital, Rotterdam, The Netherlands. The inclusion and exclusion criteria were detailed in the original publication [9]. The RCT had been approved by the Erasmus MC medical ethics review board and all parents or legal representatives had signed informed consent for the use of left-over materials in follow-up research.

Patient characteristics and clinical parameters had been prospectively collected in the context of the RCT, including age, weight, gender, disease severity scores (SOFA-score and PRISM-score), and mortality. Data on antibiotic dosing orders and co-medication were collected from the hospital records.

Blood samples were taken at PICU admission, 6, 12, and $24 \mathrm{~h}$ after admission and once daily thereafter. After analysis for the RCT, plasma samples were stored at $-80{ }^{\circ} \mathrm{C}$ for secondary use.

\section{Drug analysis}

Cefotaxime concentrations in plasma were quantified with a UPLC-MS/MS system consisting of a Dionex Ultimate UPLC system connected to a triple quadrupole mass spectrometer (Thermo TSQ Vantage with HESI-probe, Thermo Scientific) [10]. The lower and upper levels of quantification of this method were 0.13 and $12.5 \mathrm{mg} / \mathrm{l}$, respectively.

\section{Target attainment}

$\beta$-lactam antibiotics, including cephalosporins like cefotaxime, show a time-dependent pathogenic kill potential, with a pharmacodynamic target of fT $>$ MIC $>60-70 \%$, meaning that concentrations should be above the MIC for at least $60-70 \%$ of the time [11]. However, recent literature proposes fT $>$ MIC targets of $100 \%$, associated with better clinical outcome in critically ill patients [12] and even $\mathrm{fT}>4 \mathrm{xMIC}$ for a maximum killing potential in critically ill and immunocompromised patients [13].

Antibiotic plasma concentrations were compared with the clinical breakpoint for susceptibility of Neisseria meningitidis to cefotaxime $(0.125 \mathrm{mg} / \mathrm{l})$ from the European Committee of Antimicrobial Susceptibility Testing (EUCAST) [14]. Furthermore, to extrapolate our findings to other infections, comparisons were made to clinical breakpoints of Streptococcus pneumoniae $(0.5 \mathrm{mg} / \mathrm{l})$, Enterobacteriaceae $(1.0 \mathrm{mg} / \mathrm{l})$, and Staphylococcus aureus $(4 \mathrm{mg} / \mathrm{l})$, the most common causative pathogens of pediatric sepsis [15].

Since the RCT was not designed for cefotaxime PK analysis, samples were regarded to be randomly scavenged across the cefotaxime dosing interval. Furthermore, since only total drug concentrations were determined, we assumed $60 \%$ of the total concentration to be the unbound fraction of cefotaxime [16].

Two approaches to define target attainment were used as outcome measures: firstly, unbound plasma concentrations were compared with MIC and fourfold MIC values of the studied pathogens to define the percentage of samples that exceeded these target MICs. Secondly, we identified the percentage of patients at risk as patients with any unbound cefotaxime concentrations below the MIC or fourfold MIC during their ICU stay.

\section{Statistical analysis}

Data were analyzed with IBM SPSS Statistics for Windows, Version 22.0. Demographic data were analyzed using descriptive statistics and presented as "median (IQR, range)" for continuous variables and "absolute number (percentage)" for dichotomous variables.

Linear regression was performed to identify relevant covariates of cefotaxime concentrations (age, PRISM-score, SOFAscore, and serum creatinine levels). In the cases of multiple values for a single patient, i.e., for creatinine levels, data were analyzed using generalized estimating equations (GEE) to correct for within-patient variation and multiple sampling. In the case of missing data, values were imputed by linear extrapolation from adjacent data points.

\section{Results}

\section{Patient characteristics}

A total of 136 plasma samples of 37 out of 38 patients in the original RCT were available for cefotaxime analysis (1-7 
samples per patient). Patients had a median age of 2 years (range 0.3-16.1 years) and a median weight of $13.7 \mathrm{~kg}$ (range 6-70 kg). Median PRISM scores were 24 (range 4-43) and the mortality rate during admission was $24.3 \%$ (Table 1 ).

\section{Drug levels and target attainment}

Total cefotaxime plasma concentration varied widely, with a median of $8.0 \mathrm{mg} / \mathrm{l}$ (IQR $2.5-18.7 \mathrm{mg} / \mathrm{l}$ and range $0-81.1 \mathrm{mg} /$ 1). When accounting for protein binding, median unbound plasma concentrations were $4.8 \mathrm{mg} / \mathrm{l}$ (range $0-48.7 \mathrm{mg} / \mathrm{l}$ ). Cefotaxime concentrations were below the lower level of quantification in six samples, five of which had been taken at PICU admission $(t=0)$, in patients having received another cephalosporin.

The proportion of samples above the MIC of $N$. meningitides was $95.6 \%$ and above the MIC of S. pneumoniae, Enterobacteriaceae, and S. aureus in $91.2 \%$, $86.0 \%$, and $55.1 \%$ of samples, respectively. Using the higher target (fT $>4 \mathrm{xMIC}$ ), unbound plasma concentrations were above fourfold MIC of N. meningitidis in $91.2 \%$ of samples and of $S$. pneumoniae, Enterobacteriaceae, and $S$. aureus in $71.3 \%, 55.1 \%$, and $14.7 \%$, respectively (Table 2 and Fig. 1).

The proportion of patients with all of their samples above the MIC for $N$. meningitides, $S$. pneumoniae, Enterobacteriaceae, and S. aureus was $94.6 \%, 86.5 \%$, $75.7 \%$, and $51.4 \%$, respectively. For the higher target of fT $>4 \times$ MIC, this ranged from $86.5 \%$ for $N$. meningitides to $16.2 \%$ for S. aureus (Table 3).

\section{Co-variate analysis}

The relationships of age, PRISM-score, SOFA-score, and creatinine levels with cefotaxime plasma levels were explored using linear regression. Of these studied variables, only creatinine levels were weakly but significantly correlated with cefotaxime levels $\left(R^{2}=0.157, p<0.001\right)$, as shown in Fig. 2 . This association was maintained when correcting for repeated
Table 1 Demographic information of patients

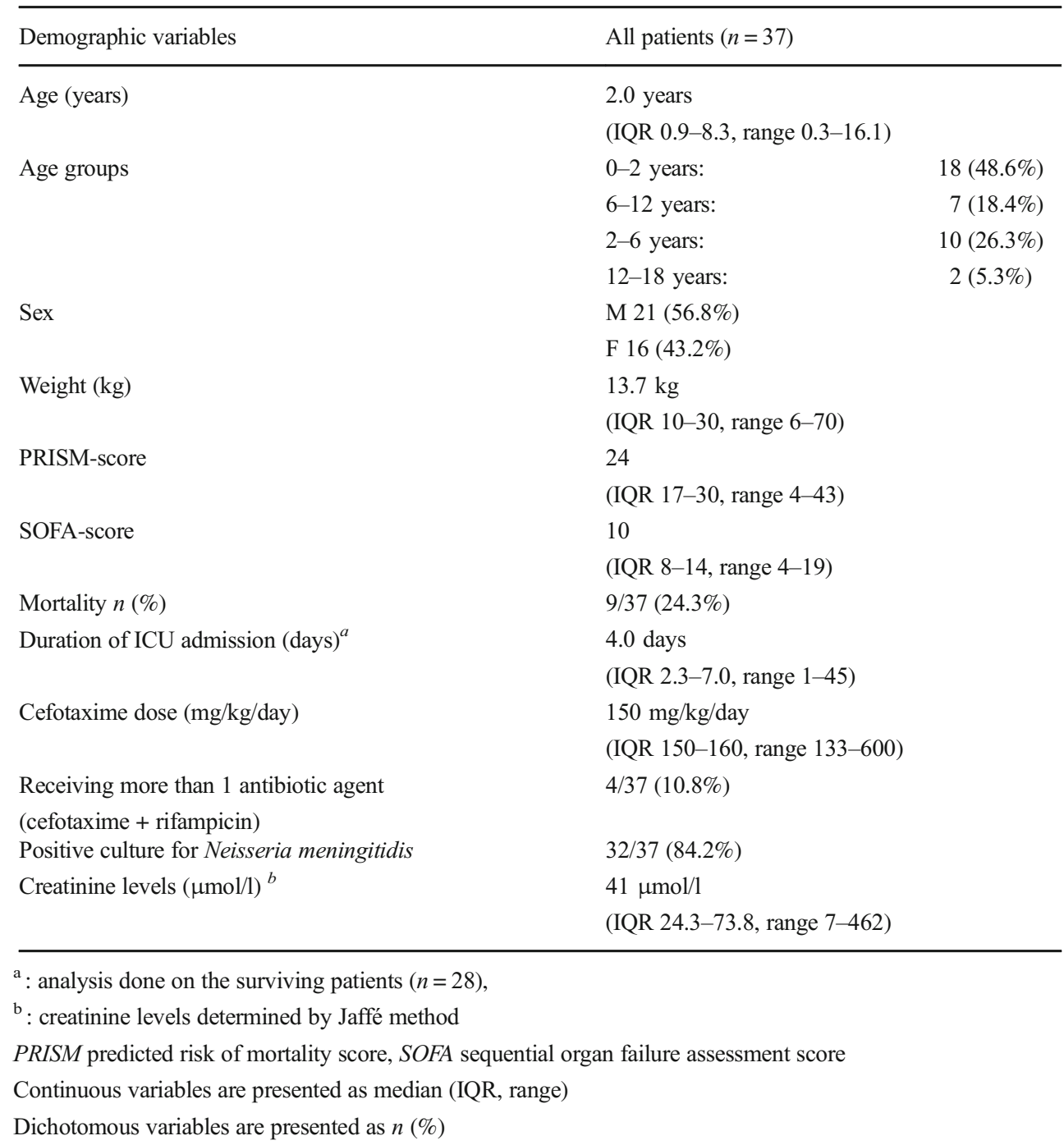


Table 2 Percentage of samples with unbound concentrations above the MIC and fourfold MIC of selected pathogens

\begin{tabular}{|c|c|c|c|c|c|c|c|c|}
\hline \multirow[t]{2}{*}{ Analysis } & \multicolumn{2}{|c|}{ N. meningitidis } & \multicolumn{2}{|c|}{ S. pneumoniae } & \multicolumn{2}{|c|}{ Enterobacteriaceae } & \multicolumn{2}{|l|}{ S. aureus } \\
\hline & $\begin{array}{l}\text { MIC } \\
(0.125 \mathrm{mg} / \mathrm{l})\end{array}$ & $\begin{array}{l}4 x M I C \\
(0.5 \mathrm{mg} / \mathrm{l})\end{array}$ & $\begin{array}{l}\text { MIC } \\
(0.5 \mathrm{mg} / \mathrm{l})\end{array}$ & $\begin{array}{l}4 \times \mathrm{MIC} \\
(2 \mathrm{mg} / \mathrm{l})\end{array}$ & $\begin{array}{l}\text { MIC } \\
(1 \mathrm{mg} / \mathrm{l})\end{array}$ & $\begin{array}{l}4 \mathrm{xMIC} \\
(4 \mathrm{mg} / \mathrm{l})\end{array}$ & $\begin{array}{l}\text { MIC } \\
(4 \mathrm{mg} / \mathrm{l})\end{array}$ & $\begin{array}{l}\text { 4xMIC } \\
(16 \mathrm{mg} / \mathrm{l})\end{array}$ \\
\hline $\begin{array}{c}n(\%) \text { of samples } \\
\text { above target } \\
\text { concentration }\end{array}$ & $\begin{array}{l}130 / 136 \\
(95.6 \%)\end{array}$ & $\begin{array}{l}124 / 136 \\
(91.2 \%)\end{array}$ & $\begin{array}{l}124 / 136 \\
(91.2 \%)\end{array}$ & $\begin{array}{l}97 / 136 \\
(71.3 \%)\end{array}$ & $\begin{array}{l}117 / 136 \\
(86.0 \%)\end{array}$ & $\begin{array}{l}75 / 136 \\
(55.1 \%)\end{array}$ & $\begin{array}{l}75 / 136 \\
(55.1 \%)\end{array}$ & $\begin{array}{l}20 / 136 \\
(14.7 \%)\end{array}$ \\
\hline
\end{tabular}

measurements within subjects using $\operatorname{GEE}(B=0.061(95 \% \mathrm{CI}$

$0.041-0.081, p<0.001)$.

\section{Discussion}

In this secondary analysis of prospectively collected data, we evaluated the hypothesis that pathophysiological changes in critically ill children with sepsis could lead to low target attainment of cefotaxime. To our knowledge, this is the first cohort of severe pediatric septic shock patients in which cefotaxime concentrations are reported.

Although most samples were well above the MIC of $N$. meningitidis, even when a higher target of four times the MIC is pursued, target attainment for less susceptible pathogens was poor, even with the most conservative target of fT $>$ MIC of $100 \%$. Therefore, using cefotaxime in current doses as blind, broad-spectrum antibiotic therapy might lead to therapy failure in children with severe sepsis caused by less susceptible pathogens.
These results are in line with recent population pharmacokinetic studies that show that critically ill children require a higher dose of $\beta$-lactam antibiotics compared with noncritically ill patients [2-7]. The study by Béranger et al. concludes that the target of fT $>$ MIC $100 \%$ is not reached with standard intermittent cefotaxime dosing in critically ill children [5]. An important difference with this population pharmacokinetic study is that our patients were more severely ill as is reflected by much higher mortality in our cohort (24.3\% vs. $2.0 \%$ ). Furthermore, kidney function was not included in their model while in our study creatinine correlated significantly, albeit weakly, with cefotaxime concentrations. This can be explained by a greater variation in kidney function in our cohort (range of creatinine $7-472 \mu \mathrm{mol} / 1$ in our cohort vs. 11-81 $\mu \mathrm{mol} / \mathrm{l})$. However, the large inter-individual variation in cefotaxime concentrations cannot be contributed to clearance alone, but could be explained by additional changes in the volume of distribution.

Béranger and colleagues propose continuous dosing to reach target attainment for patients of any age and weight.

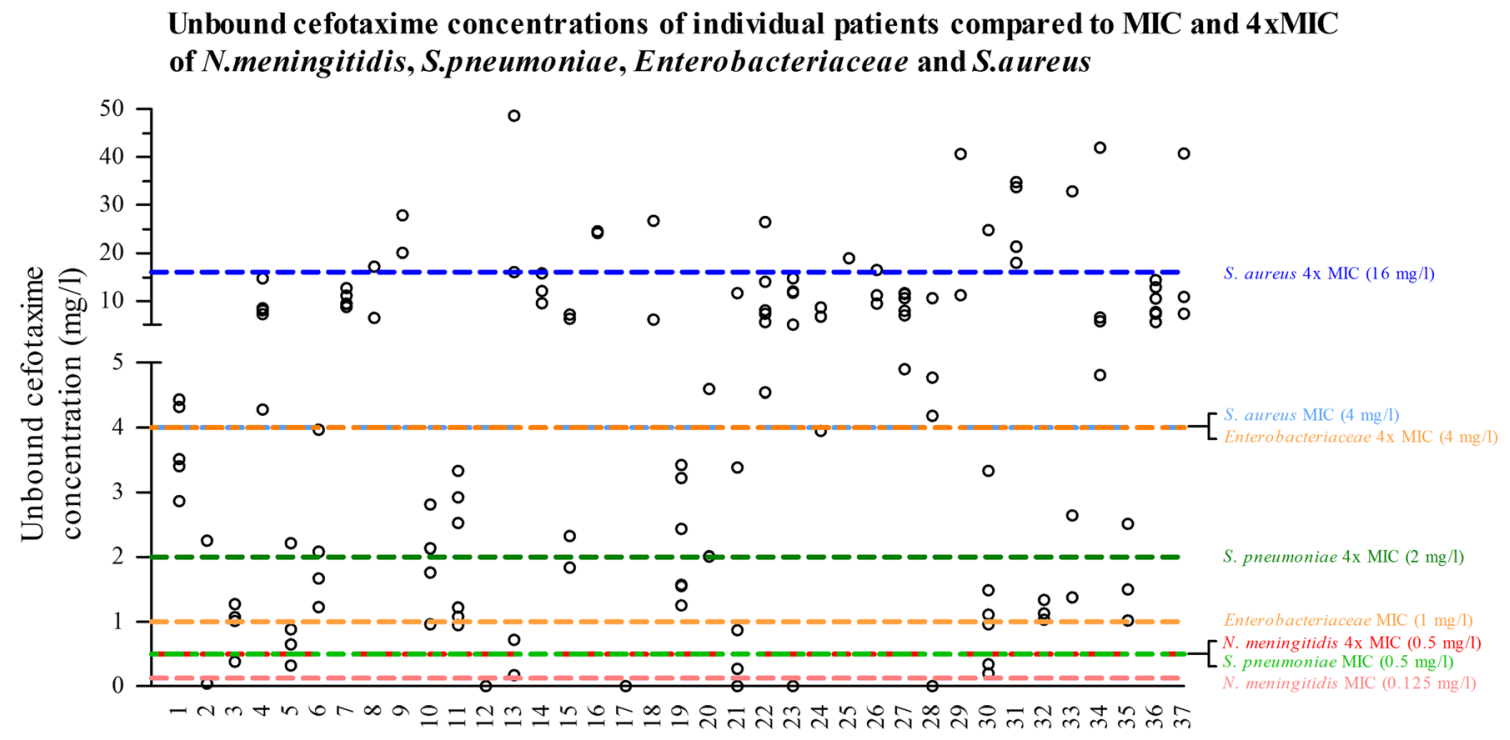

Patients

Fig. 1 Plasma concentrations of cefotaxime for each individual patient with reference lines for the MIC and fourfold MIC of $N$. meningitidis (red), S. pneumoniae (green), Enterobacteriaceae (orange), and
S.aureus (blue). The amount of samples and the number of patients with one or more samples above the MIC or fourfold MIC can be found in Tables 2 and 3, respectively 
Table 3 Percentage of patients with all unbound plasma concentrations above the MIC and fourfold MIC of selected pathogens

\begin{tabular}{|c|c|c|c|c|c|c|c|c|}
\hline \multirow[t]{2}{*}{ Analysis } & \multicolumn{2}{|c|}{ N. meningitidis } & \multicolumn{2}{|c|}{ S. pneumoniae } & \multicolumn{2}{|c|}{ Enterobacteriaceae } & \multicolumn{2}{|l|}{ S. aureus } \\
\hline & $\begin{array}{l}\text { MIC } \\
(0.125 \mathrm{mg} / \mathrm{l})\end{array}$ & $\begin{array}{l}4 \mathrm{xMIC} \\
(0.5 \mathrm{mg} / \mathrm{l})\end{array}$ & $\begin{array}{l}\text { MIC } \\
(0.5 \mathrm{mg} / \mathrm{l})\end{array}$ & $\begin{array}{l}4 x M I C \\
(2 \mathrm{mg} / \mathrm{l})\end{array}$ & $\begin{array}{l}\text { MIC } \\
(1 \mathrm{mg} / \mathrm{l})\end{array}$ & $\begin{array}{l}4 \times M I C \\
(4 \mathrm{mg} / \mathrm{l})\end{array}$ & $\begin{array}{l}\text { MIC } \\
(4 \mathrm{mg} / \mathrm{l})\end{array}$ & $\begin{array}{l}4 \times M I C \\
(16 \mathrm{mg} / \mathrm{l})\end{array}$ \\
\hline $\begin{array}{l}n(\%) \text { of patients with all } \\
\text { samples above target } \\
\text { concentration }\end{array}$ & $\begin{array}{l}35 / 37 \\
(94.6 \%)\end{array}$ & $\begin{array}{l}32 / 37 \\
(86.5 \%)\end{array}$ & $\begin{array}{l}32 / 37 \\
(86.5 \%)\end{array}$ & $\begin{array}{l}22 / 37 \\
(59.5 \%)\end{array}$ & $\begin{array}{l}28 / 37 \\
(75.7 \%)\end{array}$ & $\begin{array}{l}19 / 37 \\
(51.4 \%)\end{array}$ & $\begin{array}{l}19 / 37 \\
(51.4 \%)\end{array}$ & $\begin{array}{l}6 / 37 \\
(16.2 \%)\end{array}$ \\
\hline
\end{tabular}

Although continuous infusion is possible on the PICU, it remains cumbersome in routine care. Moreover, meta-analyses of RCTs in adults are inconclusive whether continuous infusion of $\beta$-lactam antibiotics leads to a survival benefit over intermittent dosing $[17,18]$.

Our findings suggest that antibiotic dosing guidelines should incorporate pharmacodynamic endpoints, e.g., MIC values. Current standard doses result in median unbound plasma concentrations 40-fold above the targeted values for highly susceptible pathogens like $N$. meningitidis, but for less susceptible pathogens even the most conservative target is rarely reached. Incorporating appropriate pharmacodynamic endpoints in dosing guidelines can offer tailored doses for both susceptible and less susceptible pathogens. A recent study by Woksepp et al. investigated target attainment of $\beta$-lactam antibiotics in critically ill adults based on the MIC of the cultured pathogen, compared with EUCAST clinical breakpoints [19]. They found markedly higher target attainment when using the true-MIC (89\%) compared with clinical breakpoints $(55 \%)$, which also highlights that data on susceptibility could provide valuable information to improve antibiotic dosing regimens.

Our study shows some limitations: Firstly, samples were randomly scavenged and were not collected with the purpose of evaluating drug disposition. However, since the

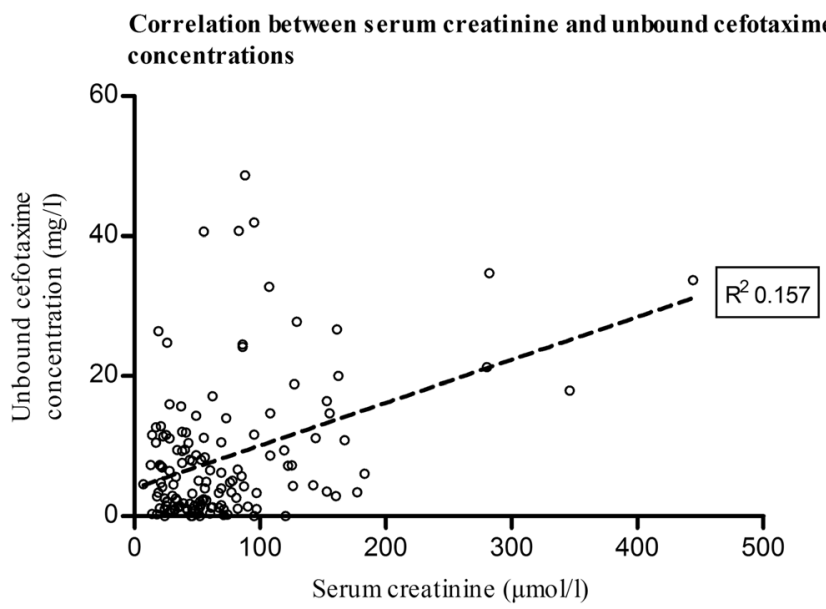

Fig. 2 Correlation between serum creatinine and unbound plasma concentrations of cefotaxime. Legend: each dot represents a single cefotaxime concentration measurement with accessory serum creatinine concentration. The solid black line represents the linear regression line $\left(p<0.001, R^{2}=0.157\right)$ pharmacodynamic target for $\beta$-lactam antibiotics is to maintain drug concentrations above the MIC for the entire dosing interval, our results represent a "best-case scenario" of target attainment of cefotaxime for these pathogens in critically ill children with severe septic shock.

Secondly, samples have been stored for a prolonged period (maximum 19 years) at $-80^{\circ} \mathrm{C}$ and underwent a single freezethaw cycle that could impact sample quality. A study comparing the effect of storage temperature for 11 different $\beta$-lactam antibiotics, including cefotaxime, shows that cefotaxime was stable after 52 weeks at $-70{ }^{\circ} \mathrm{C}$ [20]. In addition, the concentrations in our study were similar to those reported in critically ill adults [21]. Thirdly, we did not determine concentrations of cefotaxime's active metabolite desacetyl-cefotaxime, which does contribute to the antibiotic effect, but we believe it has limited influence on overall cefotaxime exposure and consequent effect [22].

\section{Conclusion}

In this secondary analysis of a prospective RCT, we have analyzed the target attainment of cefotaxime in critically ill children. Target attainment of cefotaxime seems adequate for susceptible pathogens but poor for less susceptible pathogens. Therefore, using cefotaxime with the current dosing guidelines as blind, broad-spectrum antibiotic therapy might lead to therapy failure. These findings suggest a benefit of incorporating pharmacodynamic endpoints in dosing guidelines for antibiotics. Prospective research is needed for an adequate analysis of target attainment of cefotaxime in critically ill children and identification of relevant covariates to design individualized dosing guidelines.

Funding This study was financially supported by Radboudumc, Nijmegen, the Netherlands, and Erasmus MC, Rotterdam, The Netherlands. No additional funding or grant was obtained for this research.

\section{Compliance with ethical standards}

Conflict of interest The authors declare that they have no conflict of interest. 
Ethical approval Ethical approval was obtained for the original study. No additional approval obtained for secondary analysis.

Informed consent Parents or legal representatives of all participants signed informed consent for the original trial with consent for additional analyses.

Open Access This article is distributed under the terms of the Creative Commons Attribution 4.0 International License (http:// creativecommons.org/licenses/by/4.0/), which permits unrestricted use, distribution, and reproduction in any medium, provided you give appropriate credit to the original author(s) and the source, provide a link to the Creative Commons license, and indicate if changes were made.

\section{References}

1. De Waele JJ, Lipman J, Akova M et al (2014) Risk factors for target non-attainment during empirical treatment with beta-lactam antibiotics in critically ill patients. Intensive Care Med. https://doi.org/10. 1007/s00134-014-3403-8

2. De Cock PA, Standing JF, Barker CI et al (2015) Augmented renal clearance implies a need for increased amoxicillin-clavulanic acid dosing in critically ill children. Antimicrob Agents Chemother. https://doi.org/10.1128/AAC.01368-15

3. De Cock PA, van Dijkman SC, de Jaeger A et al (2017) Dose optimization of piperacillin/tazobactam in critically ill children. $\mathrm{J}$ Antimicrob Chemother. https://doi.org/10.1093/jac/dkx093

4. Bressolle F, Gouby A, Martinez JM et al (1996) Population pharmacokinetics of amikacin in critically ill patients. Antimicrob Agents Chemother. https://doi.org/10.1128/AAC.40.7.1682

5. Béranger A, Oualha M, Urien S et al (2018) Population pharmacokinetic model to optimize cefotaxime dosing regimen in critically ill children. Clin Pharmacokinet. https://doi.org/10.1007/s40262-0170602-9

6. Roberts JA, Abdul-Aziz MH, Lipman J et al (2014) Individualised antibiotic dosing for patients who are critically ill: challenges and potential solutions. Lancet Infect Dis. https://doi.org/10.1016/ S1473-3099(14)70036-2

7. Barker CI, Standing JF, Turner MA et al (2012) Antibiotic dosing in children in Europe: can we grade the evidence from pharmacokinetic/pharmacodynamic studies - and when is enough data enough? Curr Opin Infect Dis. https://doi.org/10.1097/QCO. ob013e328353105c

8. Rosenstein NE, Perkins BA, Stephens DS et al (2001) Meningococcal disease. N Engl J Med. https://doi.org/10.1056/ NEJM200105033441807

9. de Kleijn ED, de Groot R, Hack CE et al (2003) Activation of protein $\mathrm{C}$ following infusion of protein $\mathrm{C}$ concentrate in children with severe meningococcal sepsis and purpura fulminans: a randomized, double-blinded, placebo-controlled, dose-finding study. Crit Care Med. https://doi.org/10.1097/01.CCM.0000072121. 61120.D8
10. Abdulla A, Bahmany S, Wijma RA et al (2017) Simultaneous determination of nine beta-lactam antibiotics in human plasma by an ultrafast hydrophilic-interaction chromatography-tandem mass spectrometry. J Chromatogr B Analyt Technol Biomed Life Sci. https://doi.org/10.1016/j.jchromb.2017.06.014

11. Craig WA (1995) Interrelationship between pharmacokinetics and pharmacodynamics in determining dosage regimens for broadspectrum cephalosporins. Diagn Microbiol Infect Dis. https://doi. org/10.1016/0732-8893(95)00053-D

12. McKinnon PS, Paladino JA, Schentag JJ (2008) Evaluation of area under the inhibitory curve (AUIC) and time above the minimum inhibitory concentration ( $>\mathrm{MIC}$ ) as predictors of outcome for cefepime and ceftazidime in serious bacterial infections. Int $\mathrm{J}$ Antimicrob Agents. https://doi.org/10.1016/j.ijantimicag.2007.12. 009

13. Roberts JA, Lipman J (2009) Pharmacokinetic issues for antibiotics in the critically ill patient. Crit Care Med. https://doi.org/10.1097/ CCM.0b013e3181961bff

14. The European Committee on Antimicrobial Susceptibility Testing (2017) Breakpoint tables for interpretation of MICs and zone diameters. Version 7.1. http://www.eucast.org/ast_of bacteria/previous versions_of_documents

15. Hartman ME, Linde-Zwirble WT, Angus DC (2013) Trends in the epidemiology of pediatric severe sepsis. Pediatr Crit Care Med. https://doi.org/10.1097/PCC.0b013e3182917fad

16. Luthy R, Munch R, Blaser J et al (1979) Human pharmacology of cefotaxime (HR 756), a new cephalosporin. Antimicrob Agents Chemother. https://doi.org/10.1128/AAC.16.2.127

17. Roberts JA, Webb S, Paterson D et al (2009) A systematic review on clinical benefits of continuous administration of beta-lactam antibiotics. Crit Care Med. https://doi.org/10.1097/CCM. 0b013e3181a0054d

18. Falagas ME, Tansarli GS, Ikawa K et al (2013) Clinical outcomes with extended or continuous versus short-term intravenous infusion of carbapenems and piperacillin/tazobactam: a systematic review and meta-analysis. Clin Infect Dis. https://doi.org/10.1093/cid/ cis857

19. Woksepp H, Hallgren A, Borgstrom S et al (2016) High target attainment for beta-lactam antibiotics in intensive care unit patients when actual minimum inhibitory concentrations are applied. Eur J Clin Microbiol Infect Dis. https://doi.org/10.1007/s10096-0162832-4

20. Nickolai DJ, Lammel CJ, Byford BA et al (1985) Effects of storage temperature and $\mathrm{pH}$ on the stability of eleven beta-lactam antibiotics in MIC trays. J Clin Microbiol 21(3):366-370

21. Abhilash B, Tripathi CD, Gogia AR et al (2016) Variability in plasma concentration of cefotaxime in critically ill patients in an Intensive Care Unit of India and its pharmacodynamic outcome: a nonrandomized, prospective, open-label, analytical study. J Pharmacol Pharmacother. https://doi.org/10.4103/0976-500X. 179356

22. Jones RN (1989) A review of cephalosporin metabolism: a lesson to be learned for future chemotherapy. Diagn Microbiol Infect Dis. https://doi.org/10.1016/0732-8893(89)90042-4

Publisher's note Springer Nature remains neutral with regard to jurisdictional claims in published maps and institutional affiliations. 